\title{
Pressures under normal feet in standing and walking as measured by foil pedobarography
}

\author{
D. W. GRIEVE AND T. RASHDI
}

From the Biomechanics Laboratory, Royal Free Hospital School of Medicine, Rowland Hill Street, London NW3 $2 P F$

SUMMARY An economical method of recording peak pressures under the feet while standing or walking is described for clinical application. Normal values at 10 defined locations are presented. Correlation matrices indicate functional links between regions of support which influence patterns of deviation from the norms.

Key words: hallux, heel, locomotion, metatarsus, posture, pressure.

The many devices that have been used to monitor pressures or forces under the feet, reviewed by Lord, ${ }^{1}$ fall broadly into two classes, which register either peak pressures regardless of their times of occurrence, or pressures as functions of time. The foil pedobarograph ${ }^{2}$ is one of the former, akin to those of Morton ${ }^{3}$ and Harris and Beath. ${ }^{4}$ Its novelty lies in the use of ductile aluminium foil as a recording medium which is cheap and avoids the use of ink. The records have visual impact, good spatial resolution, reflect gradations of pressure over the range encountered in both standing and walking, and may be measured quantitatively.

Pressures are presented for normal subjects, measured at 10 positions under the feet in standing and walking. Correlations between the pressures and some ancillary data are examined; their existence poses a challenge to the recognition of a normal (or any other) pattern of pressures in the individual. The videocomparator, which was used for the measurements, has how been replaced by a rapid scanning and display system which should make foil pedobarography acceptable for routine clinical use.

\section{Materials and methods}

Recording sandwich and quantification of records. Footprints were recorded as patterns of indentation on ductile aluminium foil. Foot pressure compresses the foil in a sandwich $(450 \mathrm{~mm}$ long by $250 \mathrm{~mm}$ wide) between a $5 \mathrm{~mm}$ sheet of high density foam and a rubber undermat whose upper surface is embossed with a pyramidal lattice $(3.54 \mathrm{~mm}$ repeat distance). Indentation size is a non-linear function of pressure. Calibration foils were produced by compressing the sandwich with a circular anvil under steady loading for 5 seconds. Pedobarograms were mounted on a table which could be translated horizontally without rotation. A television camera produced an image of the pyramids on a monitor. The field, split by a mirror, permitted nine pyramids of the footprint to be viewed in juxtaposition to those of a standard. The standards $\left(0-0.6 \mathrm{~N} / \mathrm{mm}^{2}\right.$, in steps of 0.05 ) were changed in the field of view until a visual match (estimated to nearest $0.025 \mathrm{~N} / \mathrm{mm}^{2}$ ) was obtained. A pointer on the table was used to align the footprint relative to the baseplate, so that sites where measurements were required could be easily located by template.

\section{SUBJECTS}

Fifty-four men and women, with no history of locomotor disorder took part. The mean and standard deviation of age, height, and weight were $29 \pm$ 13 years, $168 \pm 9 \mathrm{~cm}$, and $64 \pm 11 \mathrm{~kg}$ respectively. A further 24 normal subjects took part in a subsidiary experiment to establish the relative positions of medial and lateral landmarks in the feet and footprints.

Procedure with subjects. Height, weight, sex, age, and the total lengths and widths of both feet (along and perpendicular to the medial borders), were recorded. The standing footprints were obtained from each foot in turn, when loaded to half body weight as indicated by an eye-level indicator on a spring loaded balance board. For walking prints the 
subject stood at one end of a carpet walkway, 0.525 $\mathrm{m}$ wide and $4.43 \mathrm{~m}$ long. Two recording sandwiches were located at the centre, $0.55 \mathrm{~m}$ apart, and clearly visible to the subjects. The records were obtained by starting to walk with the right foot from a feettogether position; second placements of the right and left feet were recorded.

Statistical relationships between pressure sites and skeletal landmarks. Fifty A-P radiographs of loadbearing feet (hallux valgus range $6^{\circ}$ to $54^{\circ}$ ) were measured, together with lateral radiographs. The locations of feet, tube, and film were standardised so that the floor projections of skeletal landmarks were obtained relative to the soft tissue prominences. Foil prints from a further 24 normal subjects were related to the soft tissue prominences by marking the foil with a vertical needle. The combined statistical data gave the mean positions of the skeletal landmarks related to the medial border and first metatarsal (MT) prominence of the prints, expressed in the coordinates of percentage print width.

In the main study pressures under the hallux and heel were located by inspection. Six lines were chosen, parallel to the medial border, where maximum pressures associated with the metatarsal heads were measured. Two further locations under the lateral instep were close to extreme statistical locations of the cuboid-fifth MT joint. Coordinates of the sites are given in Table 1.

\section{Results}

Distribution of peak pressures under the foot. Table 2 gives the 2.5 and 97.5 percentile pressures and analogous confidence limits in the means observed at the 10 sites. The data relate to 116 feet, left and right combined; no significant differences of pressure were found between the two sides.

Functional correlations at $\leqslant 1 \%$ level of significance. Correlations were determined between all variables within-foot for both standing and walking (see Fig. 1), using the combined data for left and right feet (112 degrees of freedom). The same data were examined for correlations between corresponding variables in standing and walking. Correlations between left and right were then examined in both standing and walking (56 degrees of freedom).

(a) Between-foot and stand-walk comparisons.

Table 2 Pressures in standing and walking $(N=116)$

\begin{tabular}{|c|c|c|c|c|}
\hline & \multicolumn{2}{|l|}{ Stand } & \multicolumn{2}{|l|}{ Walk } \\
\hline & Mean & $S E M$ & Mean & $S E M$ \\
\hline \multicolumn{5}{|c|}{ Pressures $\left(\mathrm{N} / \mathrm{mm}^{2}\right) \times 1000$} \\
\hline Hallux & 42 & $2 \cdot 2$ & 178 & $5 \cdot 4$ \\
\hline $1 \mathrm{MT}$ & 71 & $2 \cdot 2$ & 163 & $4 \cdot 8$ \\
\hline Cleft & 73 & $2 \cdot 1$ & 179 & $3 \cdot 2$ \\
\hline $2 \mathrm{MT}$ & 78 & $2 \cdot 0$ & 212 & $3 \cdot 9$ \\
\hline $3 \mathrm{MT}$ & 79 & $2 \cdot 1$ & 197 & $3 \cdot 4$ \\
\hline $4 \mathrm{MT}$ & 68 & $2 \cdot 2$ & 160 & $3 \cdot 2$ \\
\hline $5 \mathrm{MT}$ & 52 & $1 \cdot 8$ & 97 & $3 \cdot 5$ \\
\hline Ant. $C \cdot 5 \mathrm{MT}$ & 29 & 1.9 & 88 & $3 \cdot 3$ \\
\hline Post C $-5 \mathrm{MT}$ & 20 & $2 \cdot 0$ & 47 & $3 \cdot 3$ \\
\hline Heel & 137 & $2 \cdot 5$ & 208 & $3 \cdot 8$ \\
\hline \multicolumn{5}{|l|}{ Angles (degrees) } \\
\hline Hallux & $7 \cdot 6$ & $0 \cdot 69$ & $5 \cdot 3$ & 0.62 \\
\hline Foot & $2 \cdot 8$ & 0.57 & $1 \cdot 0$ & 0.50 \\
\hline
\end{tabular}

Table 1 Skeletal landmarks: $A$ and $B=$ mean \pm 1.96 SD, $C=$ mean. Pressure sites: $A$ and $B=$ Anterior and Posterior limits of line searched for maximum pressure at distance $C$ across print. All coordinates given as percentage print width.

\begin{tabular}{|c|c|c|c|c|c|c|}
\hline \multirow{3}{*}{$\begin{array}{l}\text { Skeletal landmark } \\
\text { or }^{*} \text { pressure site }\end{array}$} & \multicolumn{3}{|l|}{ Stand } & \multicolumn{3}{|l|}{ Walk } \\
\hline & \multicolumn{2}{|c|}{ Along } & \multirow{2}{*}{$\begin{array}{l}\text { Across } \\
-C\end{array}$} & \multicolumn{2}{|c|}{ Along } & \multirow{2}{*}{ Across } \\
\hline & $A$ & $B$ & & $A$ & $B$ & \\
\hline 1st MT head centre & 8 & -11 & 13 & 14 & -4 & 16 \\
\hline${ }^{*} 1 \mathrm{MT}$ & 3 & -14 & 15 & 8 & -8 & 19 \\
\hline 2nd MT head centre & 10 & -13 & 41 & 17 & -6 & 44 \\
\hline${ }^{*} 2 \mathrm{MT}$ & 8 & -15 & 46 & 13 & -9 & 50 \\
\hline 3rd MT head centre & 4 & -20 & 55 & 10 & -13 & 58 \\
\hline *3 MT & 2 & -24 & 60 & 8 & -18 & 64 \\
\hline 4th MT head centre & -5 & -32 & 69 & 2 & -25 & 74 \\
\hline *4 MT & 8 & -34 & 76 & -2 & -28 & 79 \\
\hline 5th MT head centre & -14 & -51 & 84 & -7 & -44 & 86 \\
\hline *5 MT & -17 & -49 & 92 & -11 & -43 & 95 \\
\hline${ }^{*}$ Anterior C-5MT point & -75 & - & 72 & -67 & - & 74 \\
\hline${ }^{*}$ Posterior C-5MT point & - & -105 & 72 & - & -98 & 74 \\
\hline
\end{tabular}


Pressures at corresponding sites on both sides were strongly correlated, except at the heels in standing and at the clefts and second MT heads in walking. The latter two sites were the only sites where stand-walk correlations did not exist (in the same foot).

(b) Within-foot correlations. For both walking and standing the pressures at pairs of adjacent sites correlated positively, except at the heel, where the correlation was negative. There was additional cross-linking across the metatarsal heads. Positive and negative partial correlations $(\leqslant 1 \%$ level of significance, weight held constant) are indicated by solid and dashed lines respectively in Fig. 1.

The left and right hand diagrams illustrate correlations which are found in either standing or walking and indicate very different patterns of linking of the hallux and heads of the medial longitudinal arch with the lateral side of the foot in the two cases.

(c) Other correlations. Pressures across the MT heads except under the first, and along the lateral instep, all correlated positively with body weight in walking. Fewer correlations were found for standing. Larger feet had a greater tendency to pes planus, since pressures under the lateral instep sites in standing and at the anterior site in walking correlated with both foot length and width.

Increase of hallux valgus was associated with
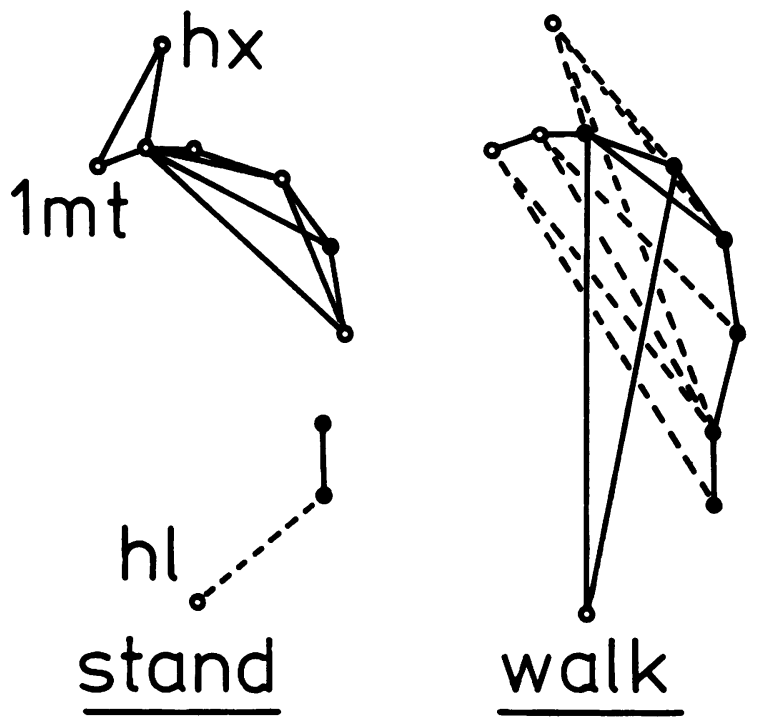

Fig. 1 Partial correlations (body weight held constant) between pressures at various sites in standing and walking. ( $\leqslant 1 \%$ level of significance). Positive and negative correlations shown by solid and dashed lines respectively. Filled circles represent sites where pressures correlate with body weight. decreased support under the heads of the medial longitudinal arch and, in walking, under the hallux also. Out-toeing correlated positively with the degree of hallux valgus in walking.

\section{Discussion}

Ten minutes was required to record from each subject. Measurement with the videocomparator was slow (15 minutes per footprint) and demanding upon the observer. One person made all the measurements; pressure ratings between and within two skilled observers were within $0.025 \mathrm{~N} / \mathrm{mm}^{2}$ in 260 out of 320 tests. The accuracy achieved with the comparator is adequate for statistical descriptions of a group, but more is needed for 'before and after' studies of individual patients. A fast computerised scanner has now been developed, giving an objective method for unskilled users, to measure to $0 \cdot 01$ $\mathrm{N} / \mathrm{mm}^{2}$ and map the whole foot if required.

The correlation matrices show that a spot reading on an individual has little value, compared with its norm, except in the context of readings at other sites. A complete map may prove more acceptable than measurements at a few key sites. The several correlations with body weight suggest that pressures should be considered after normalisation to weight.

The fast scanner makes it feasible to examine series of prints from individuals, which should give a better indication of the choices of pattern of support (available with any foot, whether normal or pathological) than can be obtained with a cross-sectional study. The method was intended for studies of hallux valgus, which will be described elsewhere. Although the patterns of mean pressures (normal versus hallux valgus) are similar in most respects, correlation matrices show a different functional linking between sites. Ways must be developed of incorporating a knowledge of the correlations into the interpretation of the foil prints.

We wish to thank the Arthritis and Rheumatism Council for financial support, the staff and students of the Chelsea School of Chiropody, and the Royal Free Hospital School of Medicine, who cooperated with facilities and acted as subjects, and Mr D. W. Wilson, FRCS, for providing radiographs and a problem requiring solution.

\section{References}

1 Lord M. Foot pressure measurement: a review of methodology. J Biomed Eng 1981; 3: 91-9.

2 Grieve D W, D'Angelo M. Spatial distributions of peak pressures under the feet as recorded by the foil pedobarograph. In: Proceedings of the December 1979 Meeting of the Anatomical Society of Great Britain and Ireland. J Anat 1980; 130; 648.

3 Morton D J. The human foot. New York: Columbia University Press, 1935.

4 Harris R I, Beath T. The short first metatarsal: its incidence and clinical significance. J Bone Joint Surg 1949; 31A: 553-63. 